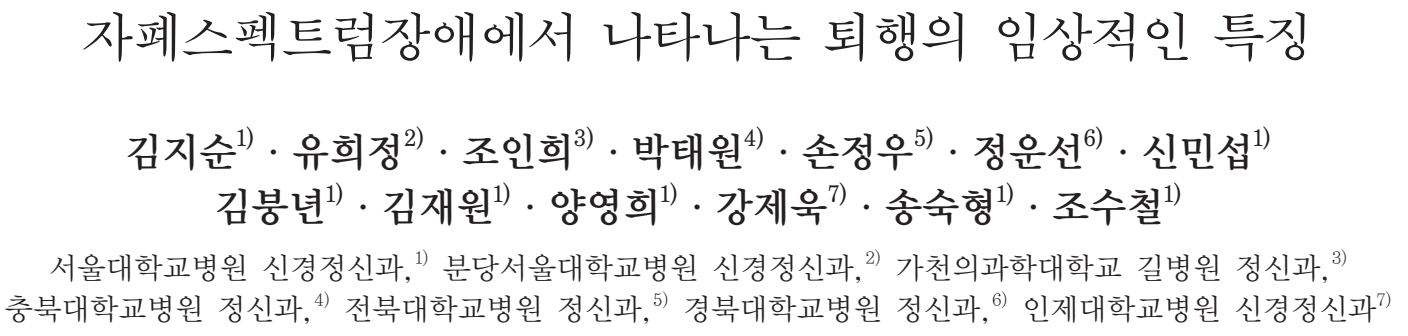

\title{
Clinical Characteristics of Developmental Regression in Autism Spectrum Disorders
}

\author{
Ji-Soon Kim, M.D. ${ }^{1}$, Hee-Jeong Yoo, M.D., Ph.D. ${ }^{2)}$, In-Hee Cho, M.D., Ph.D. ${ }^{3)}$, \\ Tae-Won Park, M.D., Ph.D. ${ }^{4)}$, Jung-Woo Son, M.D., Ph.D. ${ }^{5}$, Un-Sun Chung, M.D., Ph.D. ${ }^{6}$, \\ Min-Sup Shin, Ph.D. ${ }^{1)}$, Bung-Nyun Kim, M.D., Ph.D. ${ }^{1)}$, Jae-Won Kim, M.D., Ph.D. ${ }^{1)}$, \\ Young-Hui Yang, M.D. ${ }^{1}$, Je-Wook Kang, M.D. ${ }^{7)}$, \\ Sook-Hyung Song, M.D. ${ }^{1)}$ and Soo-Churl Cho, M.D., Ph.D. ${ }^{1)}$ \\ ${ }^{1)}$ Department of Neuropsychiatry, Seoul National University Hospital, Seoul, Korea \\ ${ }^{2)}$ Department of Neuropsychiatry, Seoul National University Bungdang Hospital, Seongnam, Korea \\ ${ }^{3}$ Department of Psychiatry, Gachon University Gill Hospital, Gachon University of Medicine and Science, Incheon, Korea \\ ${ }^{4)}$ Department of Psychiatry, Chungbuk National University Hospital, Cheongju, Korea \\ ${ }^{5)}$ Department of Psychiatry, Chonbuk National University Hospital, Jeonju, Korea \\ ${ }^{6)}$ Department of Psychiatry, Kyungpook National University, Daegu, Korea \\ ${ }^{7)}$ Department of Neuropsychiatry, Inje University Hospital, Busan, Korea
}

Objective : A significant proportion of children with autism spectrum disorders (ASD) have regression characterized by loss of previously acquired skills. The purpose of this study was to compare demographic, clinical characteristics and autism-related symptomatology of the children who have regression with children who don't have regression.

Methods : The subjects with ASD and their unaffected siblings (SIB) were recruited from the Korean Autism Genetic Study Consortium. Typically developing children (TC) were volunteered from community. The subjects were administered the Korean version of Autism Diagnostic Interview-Revised (K-ADI-R) and the Korean version of Autism Diagnostic Observation Schedule (K-ADOS) to diagnose or exclude ASD. Regression was defined on the basis of K-ADI-R data. The Korean version of Vineland Adaptive Behavior Scale (K-VABS), Aberrant Behavior Checklist (K-ABC) and Social Responsiveness Scale (K-SRS) were obtained from their parents.

Results : Regression occurred in 8.33\% $(\mathrm{n}=14)$ of children with ASD ( $\mathrm{n}=168)$. Any SIB ( $\mathrm{n}=166)$ and TC ( $\mathrm{n}=53)$ did not experience regression. Regression was associated with lower IQ and lower score of K-VABS. There was no difference in autism symptom severity and K-ABC, K-SRS scores, between children with ASD who experienced regression and who did not.

Conclusion : Regression seems to be a distinctive feature of ASD. Regression is associated with cognitive and more general functions, rather than symptoms specific to autism.

KEY WORDS : Autism Spectrum Disorders · Regression · Autism Diagnostic Interview-Revised.

접수완료 :2011년 6월 1일 / 심사완료 : 2011년 7월 27일

Address for correspondence:Soo-Churl Cho, M.D., Ph.D., Department of Neuropsychiatry, Seoul National University Hospital, 101 Daehak-ro, Jongno-gu, Seoul 110-744, Korea

Tel : +82.2-2072-3648, Fax : +82.2-744-7241, E-mail : soochur@@snu.ac.kr

이 연구는 대한민국 보건복지부의 보건의료기술진흥사업 협동 중개 연구 지원을 받았다(A080651). 


\section{서 론}

자폐장애는 사회적 상호작용과 의사소통의 질적 장애와 제 한된 관심과 상동증적인 행동을 특징으로 한다. ${ }^{1)}$ 자폐스펙트 럼장애(autism spectrum disorders, $\mathrm{ASD}$ )는 전반적 발달 장 애(pervasive developmental disorders, PDD)로도 알려져 있으며 자폐장애, 레트장애, 아동기 붕괴성 장애, 아스퍼거씨 장애, 기타 전반적 발달장애를 포함한다.) 이 진단을 받은 환 아들에서 특징적인 행동장애가 생후 첫 2년 이내에 나타나 기 시작한다. ${ }^{2)}$ 이들 중 일부는(15 47\%) 정상적인 또는 정상 에 가까운 발달기간을 가진 후 이전에 획득하였던 기능을 상 실하는 특발성의 퇴행을 보인다. ${ }^{3-5)}$ 이러한 퇴행의 유병률이 다 양하게 보고되는 것은 퇴행의 정의, 대상군의 특성, 표본의 크 기 차이에서 기인하는 것으로 생각되어진다. ${ }^{2}$ 언어기능의 상 실이 가장 흔한 유형으로 보고되었으며 이때에 다른 일반적 인 기능의 상실도 종종 동반된다. ${ }^{6.7)}$ 퇴행은 대체로 15 개월에 서 30 개월 사이에 일어났으며 생후 첫 3년 이내에 일어난 퇴행 을 조기 발달퇴행으로 따로 정의하기도 하였다. ${ }^{4)}$ 퇴행이 지속 되는 기간은 이전 연구들에서 4.7 개월에서 46개월까지 상당한 차이를 보였다. ${ }^{3,-9)}$ 퇴행이 있는 환아는 상실한 기능을 다시 획 득하기도 하지만 일부에서는 기능이 불완전하게 회복되거나 퇴행이 지속되기도 한다.2)

퇴행의 원인은 현재까지 잘 알려져 있지 않다. 퇴행과 간질 과의 관련성에 대해 보고한 연구가 있으나, ${ }^{10}$ 다른 연구에서 는 이 둘의 관련성이 입증되지 않았다. ${ }^{6,11} \mathrm{ASD}$ 환아에서 나타 나는 퇴행이 measles-mumps-rubella(MMR) 백신과 관련이 있다고 보고한 이전 연구가 있었으나, ${ }^{12)}$ 그 이후의 연구에서는 $\mathrm{ASD}$ 환아에서 나타나는 퇴행과 MMR 백신의 관련성이 없다 고 보고하였다. ${ }^{13)}$

퇴행의 유무에 따라 발달 경과의 차이가 있는지는 아직 불 분명하다. 이전의 연구들에서는 자폐증진단면담지-개정판 (Autism Diagnostic Interview-Revised, ADI-R)을 이용해 자폐증상의 심각도를 비교하였을 때, 퇴행이 있는 $\mathrm{ASD}$ 군과 퇴행이 없는 $\mathrm{ASD}$ 군 간에 차이가 없었다. ${ }^{3,14)}$ 반면에 다른 연 구에서는 $\mathrm{ADI}-\mathrm{R}$ 의 사회적 상호작용 영역에서 퇴행이 있는 $\mathrm{ASD}$ 군과 퇴행이 없는 $\mathrm{ASD}$ 군 간에 유의미한 차이를 보였 다. ${ }^{13)}$ 퇴행이 있는 ASD 환아가 그렇지 않은 환아에 비해 행동 장애를 많이 동반하거나 학교 적응력이 떨어지는 등 장기적으 로 나쁜 예후를 보였다는 보고가 있었으나, 다른 연구에서는 두 집단간에 장기적인 예후의 차이가 없었다. ${ }^{2)}$

본 연구의 목적은 $\mathrm{ASD}$ 의 일부에서 나타나는 퇴행의 빈도 와 특성을 살펴보고, 퇴행이 있는 군과 퇴행이 없는 군의 특
징을 비교함으로써 퇴행이 $\mathrm{ASD}$ 의 현상학과 원인론에서 갖는 의의를 고찰하고자 하는 것이다.

\section{방 법}

\section{1. 대상군}

본 연구에 참여한 $\mathrm{ASD}$ 아동군과 그들의 $\mathrm{ASD}$ 에 이환되지 않은 형제군은 $\mathrm{ASD}$ 의 행동 유전학연구 ${ }^{15,16}$ 의 대상군으로, 한국 자폐스펙트럼장애 유전연구컨소시엄에 참여한 대학 병 원들을 통해 모집되었다. 정상대조군은 지역사회에서 모집된 지원자로 $\mathrm{ASD}$ 를 진단받았거나 $\mathrm{ASD}$ 가 의심되는 형제나 일 차 친족이 있는 경우는 제외되었다. 모든 대상자들은 한 명 의 소아정신과 전문의에 의해 DSM-IV-TR(Diagnostic and Statistical Manual of Mental Disorders, 4th Edition, Text Revision) 기준으로 PDD 선별 과정을 거쳤다. 한국판 사회적 의사소통 설문지(Korean versions of Social Communication Questionnaire, $\mathrm{K}-\mathrm{SCQ})^{17}$ 와 한국판 아스퍼거증후군 진단척 도(Korean version of Asperger Syndrome Diagnostic Scale, $\mathrm{K}-\mathrm{ASDS})^{18)}$ 가 선별 도구로 사용되었다. 다음으로 한국판 자폐 증진단면담지(Korean version of Autism Diagnostic Interview-Revised, $\mathrm{K}-\mathrm{ADI}-\mathrm{R})^{19}$ 와 한국판 자폐증진단관찰 스케 쥴(Korean version of Autism Diagnostic Observation Sched$\mathrm{ule}, \mathrm{K}-\mathrm{ADOS})^{20}$ 을 사용하여 $\mathrm{ASD}$ 를 정밀하게 진단 또는 배 제하였다. K-ADI-R과 $\mathrm{K}-\mathrm{ADOS}$ 는 $\mathrm{ASD}$ 에서 나타나는 다양 하고 복잡한 행동 및 발달의 전 영역들을 정확히 평가하기 위 해 고안된 진단도구이다.

진단적인 타당도과 신뢰도를 높이기 위해 나이가 36개월 미 만인 대상자들을 제외하였고, 임상적으로 의미있는 신경학적 인 질환이나 심각한 내과적 질환 또는 염색체 이상이 있는 경 우도 제외하였다. 처음 모집된 $\mathrm{ASD}$ 환아군 총 176 명에서 나이 가 극한값에 해당하는 461개월인 1명, 나이가 36 개월 미만인 2 명, 퇴행 유무에 대한 자료가 없는 3명, K-ADI-R 또는 K-ADOS 에서 진단기준을 만족시키지 못하는 2 명이 제외되어, 최종적 으로 168 명이 분석에 포함되었다. 모집된 $\mathrm{ASD}$ 환아 중에서 레 트장애와 아동기 붕괴성 장애는 없었다. 또한 이환되지 않은 형제군 총 166 명에서 나이가 36개월 미만인 22명, K-ADOS 또는 K-ADI-R 진단기준을 만족시키지 못하는 13명이 제외 되어 최종적으로 131 명이 분석에 포함되었다. 정상대조군은 총 53명에서 $\mathrm{K}-\mathrm{ADOS}$ 또는 $\mathrm{K}-\mathrm{ADI}-\mathrm{R}$ 진단기준을 만족시키 지 못하는 1 명을 제외하여 최종적으로 52 명이 분석에 포함 되었다. 이 연구는 참여하는 기관들의 임상시험 윤리위원회 (Institutional Review Board, IRB)의 승인을 받았으며 대상 자들의 부모로부터 서면 동의를 받았다. 


\section{2. 평 가}

대상군의 부모에게 대상군의 적응행동을 평가하기 위한 한국판 바인랜드 적응행동척도(Korean version of Vineland Adaptive Behavior Scale, $\mathrm{K}-\mathrm{VABS})^{21)}$ 를 시행하였다. 대상군 에게는 전체 지능평가를 위해 한국판 웩슬러 아동지능검사 (Korean Educational Developmental Institute's Wechsler Intelligence Scale for Children, KEDI-WISC) 단축형, ${ }^{22}$ 동작성 지능평가를 위해서는 한국판 라이터 국제동작척도 (Korean version of Leiter International Performance Scale) ${ }^{23)}$ 를 시행하였다. 그 외 진단적이지는 않으나 $\mathrm{ASD}$ 와 직접적으 로 관련되고 비교적 흔한 행동적인 특성을 평가하기 위해 한 국판 사회적 반응척도(Korean version of Social Responsiveness Scale, K-SRS), ${ }^{24}$ 한국판 이상행동척도(Korean version of Aberrant Behavior Checklist, $\mathrm{K}-\mathrm{ABC})^{25)}$ 을 시행하 였다.

1) 한국판 사회적 의사소통 설문지(Korean version of Social Communication Questionnaire, K-SCQ)

$\mathrm{K}-\mathrm{ADI}-\mathrm{R}$ 에서 추출된 40문항의 설문을 통해 $\mathrm{ASD}$ 를 선별 하는 질문지이다. 일반적으로 부모 또는 기타 일차적인 보호 자가 개개인의 전반적인 발달력에 근거하여 "예" 또는 "아니 오”로 답하도록 되어 있으며 $\mathrm{K}-\mathrm{SCQ}$ 의 총점이 15점 또는 그 이상이 되면 $\mathrm{ASD}$ 의 가능성이 있다고 여겨지며 종합적인 평 가가 필요하다. ${ }^{17)}$

\section{2) 한국판 아스퍼거증후군 진단척도(Korean version of} Asperger Syndrome Diagnostic Scale, K-ASDS)

아스퍼거 증후군을 변별하기 위한 부모 작성용 설문지로, “예” 또는 “아니오”로 답하는 50문항으로 이루어져 있으며, 언어/사회성/부적응행동/인지/감각운동 등 5 개의 소척도로 구성되어 있다. ${ }^{18)}$

\section{3) 한국판 자폐증진단면담지(Korean version of Autism}

Diagnostic Interview-Revised, K-ADI-R)

ADI-R은 1994년 Lord 등에 의해 개발된 반 구조화된 면담 도구로, ICD-10(International Classification of Diseases, Tenth Revision) 및 DSM-III-R(Diagnostic and Statistical Manual of Mental Disorders, Third Edition, Revised)에 근 거하여 아동의 부모/보호자를 면담하는 과정을 통해 유아기 자폐증을 비롯한 $\mathrm{PDD}$ 를 진단하는 도구이다. $\mathrm{ADOS}$ 와 상보 적으로 사용되며 자폐장애 진단기준에 포함된 의사소통, 사 회적 상호작용, 행동과 관심의 제한 등 세 영역에 걸쳐 아동 의 행동양상을 포괄적으로 기술하고 평가하도록 되어 있다. 이 세 영역에 대해서는 최근 3개월간의 상태와 과거 상태에
대한 기술을 결합하여 평가하도록 되어 있다. 면담은 총 6개 의 부분(일반적 정보/초기 발달과정/의사소통과 언어/사회적 발달과 놀이/특이한 관심과 행동/비특이적인 행동문제, 특별 한 능력)으로 구성되어 있다. ${ }^{19)}$

\section{4) 한국판 자폐증진단관찰 스케쥴(Korean version of Autism Diagnostic Observation, K-ADOS)}

ADOS는 1989년 Lord 등에 의해 개발된 반 구조화된 자폐 장애 진단도구로 자폐장애 및 다른 $\mathrm{PDD}$ 를 의심하여 의뢰된 환자에서 의사소통, 사회적 상호작용, 놀이 또는 사물의 상상 적 사용을 평가하는 반 구조화되고 표준화된 평가도구이다. DSM-IV와 ICD-10에 기반하고 있으며, 이미 구미권의 수많 은 연구에서 타당도 및 신뢰도연구가 시행되어 그 유용성이 입 증되었고, $\mathrm{ADI}-\mathrm{R}$ 과 함께 자폐장애 관련 연구에서 표준으로 받아들여지는 대표적인 도구 가운데 하나이다. K-ADOS는 대상의 표현성 언어와 연령에 따라 네 가지 모듈 중 한 가지 모듈만을 시행하도록 되어 있다. 네 가지 모듈에서 공통된 항 목들만 골라 퇴행이 있는 환아군과 퇴행이 없는 환아군을 비교하였다. 공통된 항목들은 아래의 7가지이다.

'상동적인/개인 특유의 단어와 어구의 사용', '유별난 눈맞 춤, '타인을 향한 얼굴 표정', 사회적 교섭 개시의 질, '상상/ 창조성, '놀잇감/사람에 대한 기이한 감각적 흥미', '손과 손가 락, 기타 복합적인 매너리즘. ${ }^{20)}$

\section{5) 한국판 바인랜드 적응행동척도(Korean version of Vineland Adaptive Behavior Scale, K-VABS)}

부모 또는 일차 보호자와의 반 구조화된 면담을 통해 적응 적 행동을 측정하는 표준화된 도구로, 사회화/의사소통/능력 일상생활/운동능력의 네 가지 영역으로 구성되어 있다. ${ }^{21)}$

6) 한국판 웩슬러 아동지능검사(Korean Educational Developmental Institute's Wechsler Intelligence Scale for Children, KEDI-WISC) 단축형

전체 지능, 언어성 지능, 동작성 지능의 세 가지 지능지수를 산출할 수 있으며, 전체 점수와 각 연령 집단 내에서의 상대적 위치를 산출할 수 있다. 검사의 효율성을 고려하여 단축형으 로 시행하였고, 단축형 검사는 산수/어휘(언어성 검사), 빠진 곳 찾기/차례 맞추기(동작성 검사) 소검사로 전체 지능을 추정 하게 되어 있다. ${ }^{22)}$

\section{7) 한국판 라이터 국제 동작 척도(Korean version of Leiter International Performance Scale)}

현재 세계적으로 가장 널리 사용되고 있는 표준화된 비언 어적 지능측정도구로, 시각화 및 추론능력과 주의력 및 기억 력으로 크게 구분되어 있다. ${ }^{23)}$ 


\section{8) 한국판 사회적 반응척도(Korean version of Social Responsiveness Scale, K-SRS)}

부모나 교사가 답할 수 있으며 자폐장애의 질적 진단가능 성 여부에 상관없이 정량적으로 평가할 수 있는 도구이다. 사 회적 상호작용 능력의 결여, 사회적 통찰, 사회정보처리, 주고 받는 사회적 의사소통능력, 사회불안 및 회피, 자폐적 몰입과 특질을 측정한다. ${ }^{24)}$

\section{9) 한국판 이상행동 척도(Korean version of Aberrant Behavior Checklist, K-ABC)}

평가대상자를 잘 아는 일차 보호자, 교사 또는 기타 어른이 작성하는 설문지로 원래는 치료반응을 측정하기 위한 설문지 로 개발되었으나 $\mathrm{ASD}$ 관련 임상연구에 광범위하게 쓰이고 있다. 요인 분석에 따라 5 개 하위척도(자극과민성, 불안초조, 울음/무기력, 사회적 위축/상동적 행동/과잉행동, 불순응/부 적절한 말)로 구성되어 있다. ${ }^{25}$

\section{ASD 아동에서 퇴행이 있는 군의 정의}

본 연구에서 퇴행이 있는 군은 K-ADI-R를 바탕으로 정의 하였고, 퇴행과 관련된 K-ADI-R 문항은 두 가지 영역으로 나뉘어져 있다.

첫 번째는 언어 기능의 상실로, 의사소통적 언어를 한 번 획 득했다가 최소 3 개월 이상 지속되는 상실을 의미한다. 본 연구 에서 퇴행을 정의할 때 상실 이전의 의사소통적 언어 수준이 다음 4가지에 해당되는 경우를 모두 포함하였다. 1) 변화가 오 기 전 어떤 시점에 최소 5 가지 서로 다른 단어를 포함하여 의 사소통적으로 사용하면서 매일 쓰는 자발적이고 의미 있는 언어가 있었음, 2) 가끔씩의 그리고/또는 5개 미만의 단어가 자발적이고 의사소통적으로 사용됨, 3) 요구될 때 생성되는 말 또는 음성이 있었던 경우, 4) 소리내기의 자발적인 모방, 유 도된 모방이나 자발적인 의사소통적 언어는 동반되지 않음.

두 번째는 일반적인 기능의 상실로, 언어기능이 아닌 어떤
기술이 적어도 3 개월간 확립되어 매일 사용되다가 적어도 3 개월간 상당히 또는 완전히 잃어버린 상실을 의미한다.

퇴행이 있는 환아군에서 상실된 기능의 유형, 기능의 주된 상실이 처음으로 드러났을 때의 나이, 기능상실과 신체질환과 의 관련성 유무, 기능상실의 기간을평가하였다.

\section{4. 통계 방법}

범주형 변수는 카이 제곱 검정으로 각 군의 평균을 비교하 였고 연속형 변수의 평균 비교는 t-test로 하였다. 이 연구의 자 료 분석을 위하여 Statistical Package for the Social Sciences (SPSS) version 17.0을 사용하였다.

\section{결 과}

\section{1. 퇴행이 있는 군과 퇴행이 없는 군의 인구학적 특성의 비교}

최종 분석에 포함된 $\mathrm{ASD}$ 환아군 168 명 중에서 퇴행을 보 인 환아는 14 명(8.33\%)이었다. 반면에 형제군 131 명과 대조군 52 명에서 퇴행을 보이는 아동은 없었다. ASD 환아에서 퇴행 이 있는 군과 퇴행이 없는 군으로 나누어, 두 집단 간의 인구 학적인 특성과 인지기능을 Table 1에서 비교, 제시하였다. 두 집단 간의 성별, 연령은 유의미한 차이를 보이지 않았다. 반면 퇴행이 있는 환아군의 KEDI-WISC 단축형 점수와 라이터 국제 동작척도가 퇴행이 없는 환아군에 비해 통계적으로 유 의미하게 낮았다.

두 집단의 $\mathrm{K}-\mathrm{VABS}$ 의 네 가지 영역을 비교한 결과 퇴행이 있 는 환아군이 퇴행이 없는 환아군에 비해 일상생활, 운동능력, 두 영역의 점수가 유의미하게 낮았다. 반면에 두 집단의 의사 소통능력, 사회화, 두 영역의 점수 차이는 통계적으로 유의미 하지 않았다.

\section{2. 퇴행이 있는 환아군의 퇴행의 특징}

퇴행을 보인 $\mathrm{ASD}$ 환아군 총 14 명에서 언어기능의 퇴행이

Table 1. Demographic and cognitive functional characteristics of subjects*

\begin{tabular}{|c|c|c|c|}
\hline & Regression $^{\dagger}(n=14)$ & No regression $^{\dagger}(\mathrm{n}=154)$ & p-value \\
\hline Sex (\% male) & $10(71.43 \%)$ & $139(90.26 \%)$ & .056 \\
\hline Age (months, mean $\pm S D$ ) & $100.50 \pm 51.21$ & $94.66 \pm 42.10$ & .626 \\
\hline Full Scale Intelligence Quotient (mean \pm SD) & $42.40 \pm 25.54$ & $71.69 \pm 29.04$ & .029 \\
\hline Leiter International Performance Scale (mean \pm SD) & $56.89 \pm 20.54$ & $87.96 \pm 26.42$ & .001 \\
\hline \multicolumn{4}{|l|}{ K-VABS domains (mean $\pm S D$ ) } \\
\hline Communication & $50.00 \pm 24.06$ & $76.19 \pm 29.10$ & .129 \\
\hline Daily living & $48.13 \pm 16.63$ & $77.99 \pm 34.57$ & .001 \\
\hline Social & $48.25 \pm 20.30$ & $66.80 \pm 31.38$ & .103 \\
\hline Motor skills & $48.00 \pm 20.83$ & $75.25 \pm 26.96$ & .019 \\
\hline
\end{tabular}

$*: \chi^{2}$ test for comparison of frequency and t-test for analyses of differences, $\dagger:$ Children with autism spectrum disorders who regress, $\neq:$ Children with autism spectrum disorder who do not regress. SD : Standard Deviation, K-VABS : Korean version of Vineland Adaptive Behavior Scale 
있는 환아는 10 명이었으며, 일반기능의 퇴행이 있는 환아는 3 명이었다. 나머지 1 명은 두 영역의 기능퇴행이 모두 있었다. 퇴 행이 시작된 평균 나이는 31.21 개월이었으며, 퇴행을 보인 환아 군 총 14명 중 6명(42.86\%)에서 상실되었던 기능이 회복되었 다. 이들의 기능이 회복되기까지 걸리는 평균 기간은 19.5 개월 이었다. 신체적 질환이 동반된 상실을 보인 환아가 1 명이 있었 으나 의미 있게 관련되었다는 명백한 증거는 없었다. 상실된 기능의 세부적인 유형은 Table 2 와 같다.

\section{3. 퇴행이 있는 군과 퇴행이 없는 군 간의 임상적 특징 비교}

퇴행이 있는 환아군과 퇴행이 없는 환아군의 자폐증상의 심각도를 비교했을 때, 두 군의 K-ADI-R의 3가지 영역 점수 와 $\mathrm{K}-\mathrm{ADOS}$ 의 공통된 항목 7가지의 점수는 통계적으로 유 의미한 차이가 없었다.

두 집단은 $\mathrm{K}-\mathrm{SRS}$ 와 $\mathrm{K}-\mathrm{ABC}$ 의 다섯가지 영역에서도 유의 미한 차이를 보이지 않았다(Table 3).

\section{4. 퇴행의 유무에 따른 진단 분포}

$\mathrm{K}-\mathrm{ADI}-\mathrm{R}$ 에서 퇴행이 있는 환아군 14 명의 진단은 모두 자폐 증이었고 퇴행없는 환아군은 자폐증이 149명(96.8\%), 자폐증 이 아닌 $\mathrm{ASD}$ 가 5 명(3.2\%)이었다. 두 군의 K-ADI-R 진단 분 포는 통계적으로 유의미한 차이가 없었다( $\mathrm{p}>.99)$.

$\mathrm{K}-\mathrm{ADOS}$ 에서 퇴행이 있는 $\mathrm{ASD}$ 환아군의 진단은 자폐증 7 명(50\%), ASD 6명(42.9\%), ASD 진단기준을 만족하지 못한 환 아가 1 명(7.1\%)이었다. 퇴행 없는 $\mathrm{ASD}$ 환아군의 진단은 자폐증 119 명(77.3\%), 자폐증이 아닌 ASD 30명(19.5\%), ASD 진단 기준
을 만족하지 못한 환아가 5명(3.2\%)이었다. 두 군의 K-ADOS 진단분포의 차이는 통계적으로 유의하였다( $\mathrm{p}=.041)$ (Fig. 1).

\section{고 찰}

본 연구에서는 국내에서 처음으로 $\mathrm{ASD}$ 를 가진 환아의 일 부에서 나타나는 퇴행의 특징을 알아보았고, 퇴행이 있는 $\mathrm{ASD}$ 환아군과 퇴행이 없는 $\mathrm{ASD}$ 환아군의 임상적인 특징과 발달경과를 비교분석하였다. 형제군과 대조군에서는 퇴행이 있었던 아동은 없었고 $\mathrm{ASD}$ 환아군에서만 퇴행이 있었던 것 으로 보아 퇴행은 ASD 특유의 특징이라고 할 수 있다.

본 연구에서 $\mathrm{ASD}$ 환아군 총 168 명에서 14 명이 퇴행을 보였 고, 퇴행의 유병률은 $8.33 \%$ 로 이전 연구들이 보고하였던 15 $47 \%$ 에 비해 유병률이 낮게 관찰되었다. K-ADI-R은 부모의 후향적인 기억의 회상으로 시행되기 때문에 K-ADI-R을 바 탕으로 정의되는 퇴행은 부모의 기억에 따른 왜곡이 있을 수 있겠다. 1998년 ASD 환아에서 보이는 퇴행과 위장관장애가 $\mathrm{MMR}$ 백신에 의해 촉발될 수 있다는 내용의 연구 ${ }^{12}$ 발표 이후 에 서양에서는 $\mathrm{ASD}$ 환아의 부모들이 퇴행에 대한 관심을 많 이 갖게 되었고 이로 인해 퇴행에 대한 인식이 높아졌다. 이러 한 시대적 유행에 따라 부모의 퇴행에 대한 인식의 차이가 퇴 행의 유병률에 영향을 미칠 수 있다. 상대적으로 이러한 시대 적 유행의 반영이 적었던 국내에서는 퇴행의 유병률이 낮게 보 고되었을 것으로 추정된다.

또한 연구방법의 차이와 모집된 대상군의 특성에 의해 퇴

Table 2. Characteristics of the regression

\begin{tabular}{|c|c|}
\hline Characteristics & \\
\hline \multicolumn{2}{|l|}{ Classification of regression, $\mathrm{n}(\%)$} \\
\hline Language regression & $10(71.43)$ \\
\hline Non language regression & $3(21.43)$ \\
\hline Language regression and non language regression & $1(7.14)$ \\
\hline Mean age at regression (months, SD) & $31.21(8.90)$ \\
\hline \multicolumn{2}{|l|}{ Regain of Lost skills, $\mathrm{n}(\%)$} \\
\hline Regain & $6(42.86)$ \\
\hline Non-regain & $8(57.14)$ \\
\hline Duration of regression in the regained group, months (SD) & $19.50(16.34)$ \\
\hline \multicolumn{2}{|l|}{ Type } \\
\hline \multicolumn{2}{|l|}{ Language regression $\left(n=11^{*}\right)$} \\
\hline At least five meaningful words & 10 \\
\hline Communicative intent & 8 \\
\hline Syntactic skills (grammar) & 1 \\
\hline Articulation (pronunciation) & 3 \\
\hline \multicolumn{2}{|l|}{ Non-language regression $\left(n=4^{*}\right)$} \\
\hline Purposive hand movement (ability to grip/hold objects) & 2 \\
\hline Motor skills (posture, gait, coordination) & None \\
\hline Self-help skills (feeding, dress, using the bathroom, etc.) & 3 \\
\hline Constructive or imaginary play (puzzle, games, make-believe, etc.) & None \\
\hline Social engagement and responsiveness (social relatedness, interest, involvement) & 2 \\
\hline
\end{tabular}

* : Note an overlap of 1 subject who regressed in both types of skills. SD : Standard Deviation 
Table 3. Autism-related symtomatology of subjects*

\begin{tabular}{|c|c|c|c|}
\hline & Regression $^{\dagger}$ & No regression ${ }^{4}$ & p-value \\
\hline \multicolumn{4}{|l|}{ K-ADI-R domains (mean \pm SD) } \\
\hline Social & $22.07 \pm 4.68$ & $22.73 \pm 5.51$ & .667 \\
\hline Communication (verbal) & $17.25 \pm 5.39$ & $16.77 \pm 4.94$ & .792 \\
\hline Communication (nonverbal) & $11.43 \pm 3.32$ & $10.66 \pm 3.45$ & .423 \\
\hline Repetitive behaviors & $5.36 \pm 2.59$ & $5.55 \pm 2.46$ & .785 \\
\hline \multicolumn{4}{|l|}{ K-ADOS domain (mean \pm SD) } \\
\hline Stereotypical/idiosyncratic use of words or phrases & $0.36 \pm 0.75$ & $0.61 \pm 0.74$ & .224 \\
\hline Unusual eye contact & $1.43 \pm 0.94$ & $1.61 \pm 0.80$ & .421 \\
\hline Facial expression directed to others & $1.29 \pm 0.47$ & $1.29 \pm 0.55$ & $>.999$ \\
\hline Quality of social overtures & $1.21 \pm 0.58$ & $1.31 \pm 0.51$ & .496 \\
\hline Imagination/creativity & $1.50 \pm 0.65$ & $1.35 \pm 0.59$ & .355 \\
\hline Unusual sensory interest in play material/person & $0.64 \pm 0.84$ & $0.53 \pm 0.74$ & .578 \\
\hline Hand and finger and other complex mannerisms & $0.29 \pm 0.61$ & $0.46 \pm 0.74$ & .393 \\
\hline \multicolumn{4}{|l|}{ K-SRS (mean $\pm S D)$} \\
\hline & $95.54 \pm 25.81$ & $95.26 \pm 28.03$ & .973 \\
\hline \multicolumn{4}{|l|}{ K-ABC domains (mean $\pm S D$ ) } \\
\hline Irritability/agitation & $12.29 \pm 9.93$ & $9.08 \pm 7.88$ & .158 \\
\hline Lethargy/social withdrawal & $15.50 \pm 10.68$ & $11.99 \pm 7.84$ & .123 \\
\hline Stereotypic behavior & $5.93 \pm 5.40$ & $4.00 \pm 4.07$ & .102 \\
\hline Hyperactivity/Noncompliance & $16.71 \pm 10.91$ & $15.30 \pm 10.28$ & .625 \\
\hline Inappropriate speech & $3.07 \pm 3.58$ & $3.14 \pm 2.62$ & .925 \\
\hline
\end{tabular}

$*: t$ - test for analyses of differences, $\dagger$ : Children with autism spectrum disorders who regress, $\ddagger$ : Children with autism spectrum disorder who do not regress. SD : Standard deviation, K-ADI-R : Korean version of Autism Diagnostic Interview-Revised, K-ADOS : Korean version of Autism Diagnostic Observation Schedule, K-SRS : Korean version of Social Responsiveness Scale, K-ABC : Korean version of Aberrant Behavior Checklist

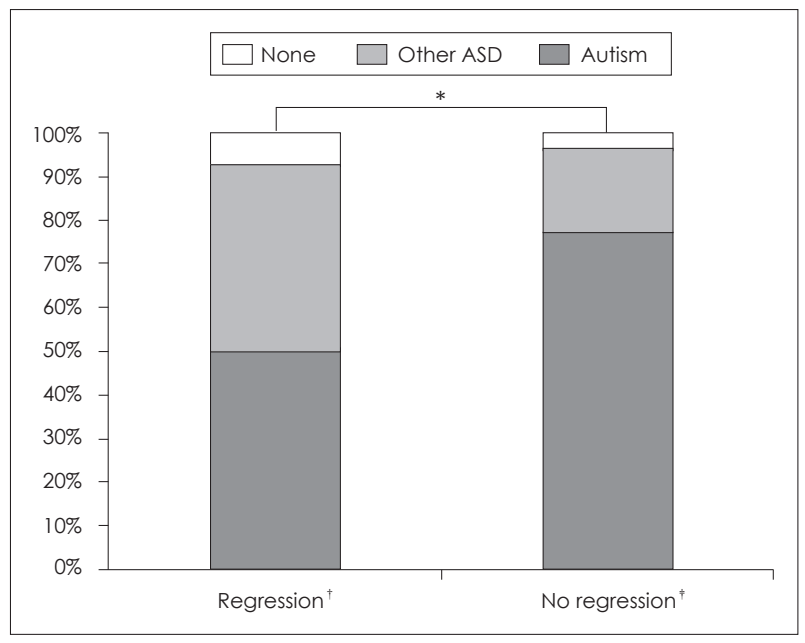

Fig. 1. Diagnostic category in K-ADOS according to presence of regression. $*: \mathrm{p}<.05, \dagger:$ Children with autism spectrum disorders who regress, $\ddagger$ : Children with autism spectrum disorder who do not regress. K-ADOS : Korean version of Autism Diagnostic Observation Schedule, ASD : autism spectrum disorders.

행의 유병률이 다를 수 있다. Davidovitch는 47\%의 높은 유 병률을 보고하였는데 분석에 포함된 환아수가 40명으로 표 본수가 적었다. 그리고 객관적인 진단도구가 아닌 설문지를 통 해 자료를 수집하였고, 발달 중 어떠한 기능의 상실도 퇴행으
로 정의하였다. ${ }^{26)}$ 이처럼 퇴행의 정의가 광범위하고 표본 수가 적었기 때문에 퇴행의 유병률이 높았을 것으로 생각된다.

Dyches는 이전의 연구들이 주로 백인만을 대상으로 시행되 었던 점을 한계점으로 제시하면서 자폐증의 유병률이 인종 에 따라 다를 수 있음을 보고하였다. ${ }^{27)} \mathrm{ASD}$ 의 퇴행에 대한 연구들도 대부분 구미권에서만 시행되었기 때문에 퇴행의 유 병률에 차이가 나는 점을 모집된 대상군의 특성 차이 또는 인종 간의 차이에 의한 가능성을 생각해 볼 수 있다. 퇴행의 유병률에 대해 아시아권에서 보고된 이전 연구결과는 거의 없으나 유일하게 중국에서 발표된 연구가 있다. ${ }^{28)}$ 이 연구에서 는 퇴행의 유병률이 $21.7 \%$ 로 보고되었으나 대상군의 나이가 30 개월에서 78 개월로, 본 연구보다 대상군의 나이가 어리기 때문에 부모에 의해 후향적으로 보고된 퇴행의 비율이 더 높 았을 것으로 추정된다.

퇴행이 시작되는 평균 나이는 31.21 개월로 15 개월에서 30 개 월 사이에 퇴행이 시작된다고 보고하였던 이전 연구들에 비해 퇴행이 늦게 시작되었다. 본 연구에서 퇴행이 있는 환아군 14 명 중 2명이 36 개월 이후에 퇴행을 보였다. 두 환아는 모두 언 어 기능의 퇴행을 보였고 이 중 한 명은 퇴행된 기능을 재 획 득하였고 나머지 한 명은 평가 당시 여전히 퇴행을 보이고 있 
었다. Parr은 ASD 환아 일부에서 36개월 이후에 퇴행을 보이 기도 하며 36 개월 이후에 퇴행을 보인 군이 상대적으로 36 개 월 이전에 퇴행을 보인 환아군에 비해 일반기능의 상실이 많 다고 보고하였다. ${ }^{29)}$ 앞으로 퇴행군의 표본수가 증가된다면 퇴행을 일찍 보이는 환아군과 상대적으로 늦게 보이는 환아 군으로 나누어 이 두 군을 통계적으로 비교해 볼 수 있겠다.

본 연구에서 퇴행이 있는 환아군이 퇴행이 없는 환아군에 비해 전체 지능과 동작성 지능이 통계적으로 유의미하게 낮 았다. 이전 연구에서 두 $\mathrm{ASD}$ 군 간의 언어성 지능의 유의미한 차이를 보인 결과와 일치한다. ${ }^{13)}$ 퇴행이 있는 환아군이 퇴행 이 없는 환아군에 비해 일상생활 능력과 운동기능이 저하된 것으로 나왔다. 반면에 두 군 간의 자폐증상 심각도의 차이는 발견하지 못했다. 이러한 결과는 퇴행의 증상이 자폐증상 심각 도를 특이적으로 반영하기 보다는 인지기능, 적응기능과 같은 좀 더 일반적인 기능과 관련이 있음을 시사한다.

본 연구에서 퇴행이 있는 군과 퇴행이 없는 군 간의 $\mathrm{K}-\mathrm{AD}-$ OS에 따른 진단적 분포에 차이가 있었다. 자폐증의 진단비율 은 퇴행이 있는 환아군에서 퇴행이 없는 환아군에 비해 통계 적으로 유의하게 낮았다. 자폐증을 진단하기 위해서는 자폐 증상의 시작이 36 개월 이전에 시작되어야 한다는 제한이 있다. 본 연구에서는 퇴행이 시작된 평균 나이가 31.21 개월로, 퇴행 이전에 정상적인 또는 정상에 가까운 발달 기간을 가진 후 기 능장애의 발생 시점이 상대적으로 퇴행이 없는 환아들에 비해 늦었을 가능성이 있다. 이로 인해 자폐증의 진단기준을 만족 하지 못하고 기타 전반적 발달장애로 진단받았을 가능성을 생각해 볼 수 있다.

본 연구는 국내에서 처음으로 진행된 ASD에서 나타나는 퇴행에 대한 연구이며, $\mathrm{ASD}$ 를 진단하고 배제하는데 있어 $\mathrm{K}-\mathrm{ADI}-\mathrm{R}, \mathrm{K}-\mathrm{ADOS}$ 같은 표준적인 진단법을 사용하여 진 단의 신뢰도를 높인 것이 장점으로 생각된다. $\mathrm{K}-\mathrm{ADOS}$ 는 언 어 사용능력에 따라 적용하는 모듈이 다르고 각각 모듈의 하위 항목의 차이가 있다. 이에 본 연구에서 공통된 7가지 하 위 항목만을 골라 증상의 심각도를 비교함으로써 $\mathrm{K}-\mathrm{ADOS}$ 의 총점을 비교하는 것에 비해 환아의 언어능력에 따른 점수 의 차이를 줄일 수 있었다.

본 연구의 제한점은 아동의 정상발달에 대한 정보가 부모 의 후향적인 기억의 회상으로 얻었기 때문에 기억의 왜곡에 따른 인식의 차이가 있을 수 있다는 점이다.

\section{결 론}

퇴행은 $\mathrm{ASD}$ 고유의 특징이므로 4세 이전의 아동이 급성 신 경학적 증후없이 이전에 획득되었던 기능의 상실을 보인다면
$\mathrm{ASD}$ 에 대한 평가를 고려해야한다. 앞으로 큰 규모의 전향적 인 연구를 통해 퇴행이 있는 환아군과 퇴행이 없는 환아군 의 차이점을 찾는다면 다른 기저의 병인에 대해서도 생각해 볼 수 있고 $\mathrm{ASD}$ 진단뿐 아니라 치료 및 예방에도 도움이 될 수 있겠다.

중심 단어 : 자폐스펙트럼장애 · 퇴행 · 자폐증진단면담지.

\section{References}

1) American Psychiatric Association. Diagnostic and statistical manual of mental disorders, 4th ed. Washington DC: American Psychiatric Press;2000.

2) Stefanatos GA. Regression in autistic spectrum disorders. Neuropsychol Rev 2008;18:305-319.

3) Lord C, Shulman C, DiLavore P. Regression and word loss in autistic spectrum disorders. J Child Psychol Psychiatry 2004;45:936955.

4) Rogers SJ. Developmental regression in autism spectrum disorders. Ment Retard Dev Disabil Res Rev 2004;10:139-143.

5) Stefanatos GA, Kinsbourne M, Wasserstein J. Acquired epileptiform aphasia: a dimensional view of Landau-Kleffner syndrome and the relation to regressive autistic spectrum disorders. Child Neuropsychol 2002;8:195-228.

6) Baird G, Charman T, Pickles A, Chandler S, Loucas T, Meldrum $\mathrm{D}$, et al. Regression, developmental trajectory and associated problems in disorders in the autism spectrum: the SNAP study. J Autism Dev Disord 2008;38:1827-1836.

7) Goldberg WA, Osann K, Filipek PA, Laulhere T, Jarvis K, Modahl $\mathrm{C}$, et al. Language and other regression: assessment and timing. J Autism Dev Disord 2003;33:607-616.

8) Shinnar S, Rapin I, Arnold S, Tuchman RF, Shulman L, BallabanGil K, et al. Language regression in childhood. Pediatr Neurol 2001; 24:183-189.

9) Wilson S, Djukic A, Shinnar S, Dharmani C, Rapin I. Clinical characteristics of language regression in children. Dev Med Child Neurol 2003;45:508-514.

10) Jones LA, Campbell JM. Clinical characteristics associated with language regression for children with autism spectrum disorders. J Autism Dev Disord 2010;40:54-62.

11) Luyster R, Richler J, Risi S, Hsu WL, Dawson G, Bernier R, et al. Early regression in social communication in autism spectrum disorders: a CPEA Study. Dev Neuropsychol 2005;27:311-336.

12) Wakefield AJ, Murch SH, Anthony A, Linnell J, Casson DM, Malik $\mathrm{M}$, et al. Ileal-lymphoid-nodular hyperplasia, non-specific colitis, and pervasive developmental disorder in children. Lancet 1998; 351:637-641.

13) Richler J, Luyster R, Risi S, Hsu WL, Dawson G, Bernier R, et al. Is there a 'regressive phenotype' of autism spectrum disorder associated with the measles-mumps-rubella vaccine? A CPEA study. J Autism Dev Disord 2006;36:299-316.

14) Fombonne E, Chakrabarti S. No evidence for a new variant of measles-mumps-rubella-induced autism. Pediatrics 2001;108:E58.

15) Nam BR, Yoo HJ, Cho IH, Park TW, Son JW, Chung US, et al. Prenatal, perinatal and infancy history of autism spectrum disorder. J Korean Acad Child Adolesc Psychiatry 2010;21:153-160.

16) Cho SC, Yoo HJ, Park M, Cho IH, Kim BN, Kim JW, et al. Genome-wide association scan of Korean autism spectrum disorders with language delay: a preliminary study. Psychiatry Investig 2011; 8:61-66.

17) Yoo HJ. Korean version of Social Communication Questionnaire (SCQ). Seoul: Hakji-sa;2008. 
18) Kim JH, Shin MS. A study of reliability and validity for the Korean version of Asperger Syndrome Diagnostic Scale. J Korean Acad Child Adolesc Psychiatry 2005;16:98-105.

19) Yoo HJ. Korean version of Autism Diagnostic Interview-Revised (ADI-R). Seoul: Hakji-sa;2007.

20) Yoo HJ, Kwak Y. Korean version of Autism Diagnostic Observation Schedule (ADOS). Seoul: Hakji-sa;2007.

21) Lee YJ, Lee JS, Yang OS. Research on development of the Adaptive Behavior Scales for young Children. Kor Soc Early Child Educ 1988; 8:87-105.

22) Park KS, Yoon JR, Park HJ, Kwon KO. Korean Educational Developmental Institute-Wechsler Intelligence Scale for Children (KEDIWISC). Seoul: Korean Educational Development Institute;2002.

23) Roid GH, Miller LJ, Leiter RG. Leiter International Performance Scale-Revised: examiners manual. Wood Dale, IL: Stoelting;1997.

24) Constantino JN, Davis SA, Todd RD, Schindler MK, Gross MM, Brophy SL, et al. Validation of a brief quantitative measure of autistic traits: comparison of the social responsiveness scale with the autism diagnostic interview-revised. J Autism Dev Disord 2003;33:
427-433.

25) Brinkley J, Nations L, Abramson RK, Hall A, Wright HH, Gabriels $\mathbf{R}$, et al. Factor analysis of the aberrant behavior checklist in individuals with autism spectrum disorders. J Autism Dev Disord 2007; 37:1949-1959.

26) Davidovitch M, Glick L, Holtzman G, Tirosh E, Safir MP. Developmental regression in autism: maternal perception. J Autism Dev Disord 2000;30:113-119.

27) Dyches TT, Wilder LK, Sudweeks RR, Obiakor FE, Algozzine B. Multicultural issues in autism. J Autism Dev Disord 2004;34:211222.

28) Xi CY, Hua TY, Zhao YJ, Liu XM. [Characteristics of developmental regression in autistic children]. Zhongguo Dang Dai Er Ke Za Zhi 2010;12:781-783.

29) Parr JR, Le Couteur A, Baird G, Rutter M, Pickles A, Fombonne E, et al. Early developmental regression in autism spectrum disorder: evidence from an international multiplex sample. J Autism Dev Disord 2011;41:332-340. 